\author{
Military Technical College \\ Kobry El-Kobbah, \\ Cairo, Egypt
}

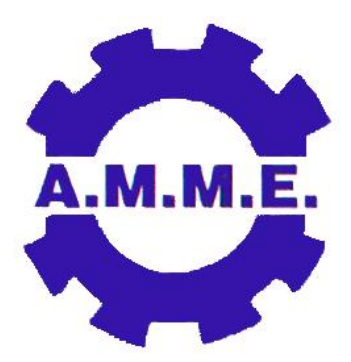

14th International Conference on Applied Mechanics and Mechanical Engineering.

\title{
Comparative Study of Point Supply/Exhaust Ventilation Systems of Road Tunnel using Numerical Simulation
}

By
N. S. Khadour*
A. A. EIMaihy*
A. G. M. Ibrahim*
S. E. Elshamarka*

\section{Abstract:}

This study presents a numerical simulation, using FLUENT ver. 6.3, for a point supply ventilation system (PSVS) of full-scale road tunnel. The conducted simulations are used to evaluate the effectiveness of the ventilation system by analyzing the numerical predictions of temperature, visibility and $\mathrm{CO}$ concentration fields for different sizes of tunnel fire namely; 5, 10, 20 and $40 \mathrm{MW}$. Numerical simulations predicted the overall flow field and gave valuable estimates of the temperatures, visibility and $\mathrm{CO}$ distribution throughout the tunnel. The hazard areas are determined according to environmental limitations established by National Fire Protection Association (NFPA) of United States. A comparison of PSVS and point exhaust ventilation system (PEVS) is also carried out to predict the hazard areas in the tunnel for both systems. The PEVS accomplishes NFPA limitations almost for all fire sizes. While, PSVS fails to do at fire sizes higher than $5 \mathrm{MW}$. These conclusions are true for the range of fire sizes and tunnel configuration considered in this study. The results of the study suggest the use of multiple openings at different locations on the tunnel ceiling and according to the fire location; one or more opening (the closest to the fire location) can be chosen to operate.

\section{Keywords:}

Road tunnel, Ventilation, Point supply, Point exhaust, and Numerical simulation 
* Egyptian Armed Force

\section{Introduction:}

Ventilation systems are essential in the design of all road tunnels. The role of ventilation systems is to maintain acceptable levels of contaminants produced by vehicles during normal traffic operation (normal ventilation), and to control heavy smoke in event of fire (emergency ventilation). In the early years of tunneling, ventilation engineers were mainly concerned with normal operation. In the last two decades however their attention has been increasingly focused on the fire case. This is due to a significant reduction of motor-vehicle emissions and to a growing concern related to safety. This trend increased dramatically owing to number of recent tragic tunnel fires [1].

In the event of fire in road tunnel and due to its confining geometry, smoke generated from the fire could severely impede visibility and evacuation. Mechanical ventilation systems such as longitudinal, transverse and semi-transverse ventilation systems are commonly employed. The effectiveness of the ventilation system in event of fire is determined by its capability to maintain a tenable environment for occupants to escape.Ventilation requirements are specified by national codes and international standards. A code compliant ventilation system design may, in some circumstances, result in being over sized or poor performance. Therefore, designing the system on performance basis may achieve cost reductions and design benefits.

In performance-based design, three different approaches can be cited: reduced-scale models, full-scale tests and numerical models. In the first, significant contributions can be found in the literature [2-4], though their results are difficult to extrapolate to different operating conditions or configurations. In the second, fire tests are carried out to assess the smoke removal capacities of the tunnel ventilation systems. It is not practical to investigate every configuration experimentally after being constructed. Also, the tests are limited to fires of lower capacity to avoid damaging the tunnel ceiling or the tunnel itself. Full-scale tests are really expensive and only two of them have been conducted recently: EUREKA Project [5] and Memorial Tunnel Fire Ventilation Test Program (MTFVTP) [6]. They require of large experimental facilities, that are difficult to operate and maintain in order to obtain good results. The literature review of the last method (numerical modeling) explored different approaches of numerical models.

a. Network Models

A tunnel, or network of tunnels and passageways, is divided into a circuit of onedimensional ventilation pathways. Solving for the conservation of mass and energy at each junction, a network model predicts the time dependent movement of air (and smoke) through the network. The strength of these models is their ability to predict air movement within the entire network at short computing time-scales. Their weakness is the missing details at the fire source and the absence of any three-dimensional effects. However, used in combination with a zone or CFD model in the vicinity of the fire source, they provide potentially a very powerful design tool. TRANSIT [7] and RABBIT [8] are recent examples of one-dimensional network models.

b. Zone Models

In a zone model the tunnel is divided into a number of zones, in which conditions at each zone are assumed to be uniform. Whilst widely used in the study of building fires, zone modeling has enjoyed less application in tunnel fires. FASIT [9] is an example of a time dependent zone model, where the fire source is represented as a Gaussian thermal 
plume. Zone models provide some of the information missing in the network models. However, the assumptions required in the plume shape, ventilation flow pattern etc, means that care must be taken not to be used out of context.

\section{c. Computational Fluid Dynamics (CFD) Models}

Based on first principles, CFD models solve the underlying conservation equations for mass, momentum, energy and species concentrations (e.g. fuel mixture fraction). This allows the important physical and chemical processes and their interactions, describing the production and movement of smoke and heat, to be simulated realistically. Physical sub-models describe the complex physical processes of turbulence, combustion and thermal radiation. In addition to general purpose commercial codes such as, JASMINE [10], Flow 3D[11], PHOENICS [12], and FLUENT [13], there are a number of special purpose CFD codes for application to tunnel fire such as SOLVENT [14], FDS [15], TUNFIRE [16]. The fire specific codes may employ simpler meshes and numerical schemes. In order to be completely reliable, the CFD codes must be calibrated and validated through comparison with experimental data. Skilful users are necessary; otherwise the obtained results may be quite misleading.

As summary, all models are potentially useful. Thus the simpler models are ideal for repeated applications, such as would be required in risk assessment. The details of geometry and ventilation system can be represented, taking advantage of 3dimensional prediction capability of CFD codes. The main advantage of the CFD models is to allow the study of cases for which no experimental data are available. The major restriction is the time needed for the calculation and the complex utilization.

A previous study [17] has been conducted which validated the use of general purpose commercial CFD code (FLUENT ver. 6.3) for modeling flow field in full-scale road tunnel incorporating a ventilation system under fire incident. The objective of this study is to assess tunnel emergency ventilation system, utilizing the validated CFD model in the previous study. PSVS and PEVS have been selected here. They are much similar to longitudinal ventilation system but more simple in construction, operation and control. They apply a unidirectional airflow through a single opening located in the ceiling of the tunnel. They represent a competitive alternative especially where natural ventilation is not recommended for long tunnels in event of fire.

The performance assessment is conducted by analyzing the CO concentration, temperature, and visibility fields for different operating conditions. The numerical results are cross-checked against environmental limitations of NFPA [18] to obtain knowledge about the hazard areas in the tunnel for both systems. Also, a comparative study between PSVS and PEVS is carried out.

\section{CFD Simulation Technique}

CFD simulation was used to predict the thermal environment of the Memorial Tunnel for test cases $320 \mathrm{~A}$ and $321 \mathrm{~A}$ of the MTFVTP, [6]. Simulations were made using FLUENT ver. 6.3 with its pre-processor GAMBIT [19].

The Memorial Tunnel has a two-lane, 853 meter long road tunnel. It is a part of the West Virginia Turnpike near Charlestown, West Virginia, USA. The tunnel is $3.2 \%$ upgrade from south to north portal. The cross-sectional area of the tunnel is $60.4 \mathrm{~m}^{2}$ without ceiling and $36.2 \mathrm{~m}^{2}$ when the ceiling is in place. Test $320 \mathrm{~A}$ investigates PEVS, while Test $321 \mathrm{~A}$ investigates PSVS. Fire source is located at the approximate quarter 
point of the tunnel $(238 \mathrm{~m})$ from the south portal. Ventilation air passes through a $28 \mathrm{~m}^{2}$ opening on the ceiling located $135 \mathrm{~m}$ north of the fire source centre line, opening no. 4 , figure (2).

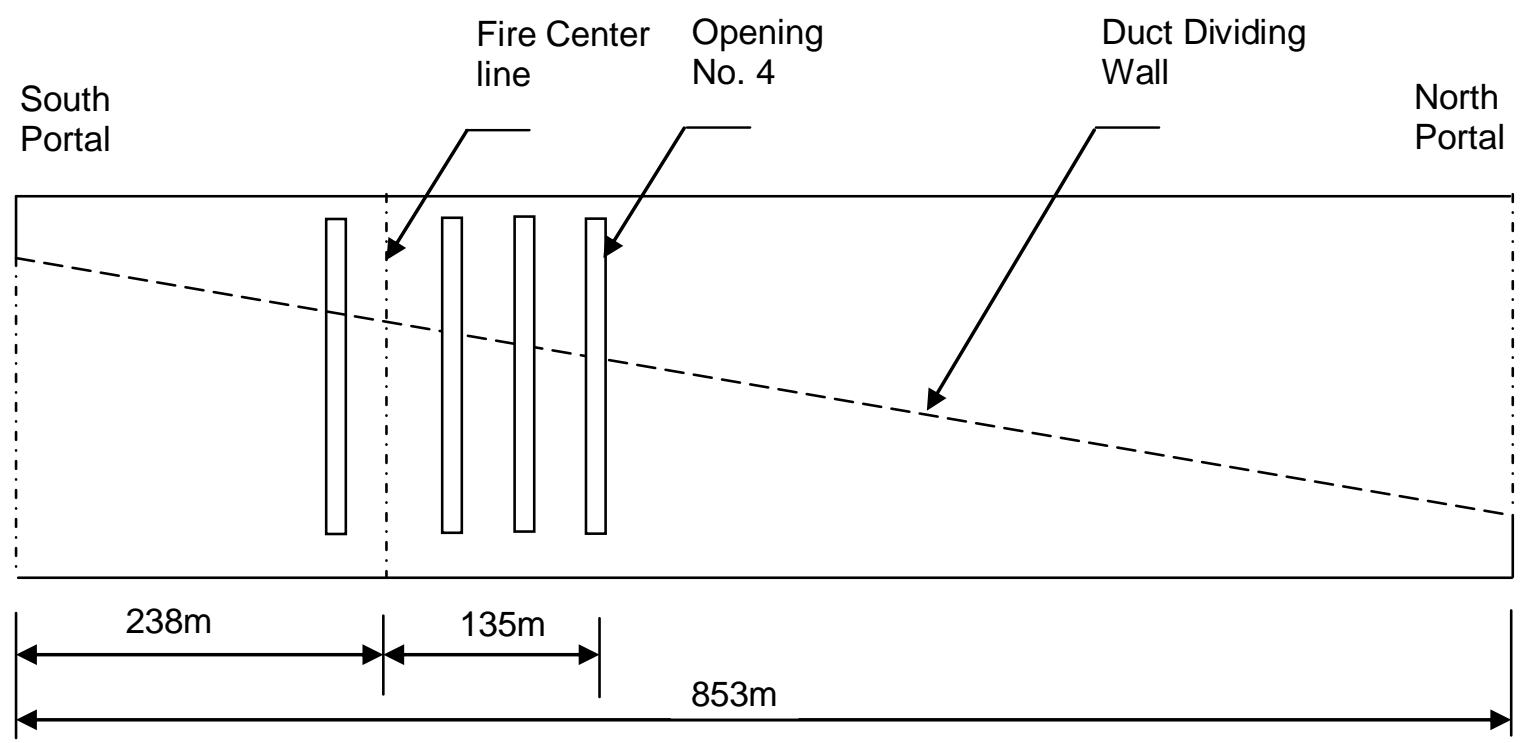

Fig (2): Memorial Tunnel duct configuration for point supply / exhaust operation, [6]

The details of the numerical model are presented in previous paper, [17]. For validation purpose, the critical velocities during a fire incident were predicted and compared with published experimental data [6]. As a result, good agreement was achieved in all the tested cases. The numerical results were obtained using PC (3.0 GHz Pentium 4), 2 GB RAM, and 120 GB HD. Generally 800-1200 initiations were required to obtain a suitable level of solution convergence, while each calculation required about 8 hours of CPU time and 40-50 MB of HD memory.

\section{Results and Discussions}

Steady-state simulations were carried out with design volumetric flow rate of $84 \mathrm{~m}^{3} / \mathrm{s}$ of ventilation air for different fire sizes namely 5, 10, 20 and $40 \mathrm{MW}$ which simulates the HRR results from firing different types of vehicles. Simulation results make it possible to detect a priori the maximum level of toxicity, visibility conditions and threshold of human resistance to high temperatures in a fire incident. This information may determine if the design of the ventilation system is correct. If it is not, it may be useful to define corrective actions in order to improve the rescue plans.

Simulation results are presented as contours of $\mathrm{CO}_{2}$ and temperature on the symmetry plane. The real affection zone comprises $2 \mathrm{~m}$ height from the road for the standing people trapped inside and $1 \mathrm{~m}$ height for people inside vehicles. Therefore, the $\mathrm{CO}$ and temperature are plotted against longitudinal distance through the tunnel at two levels of 1 and $2 \mathrm{~m}$. The visibility, which is obtained mainly from the axial velocity distributions, is plotted against the longitudinal distance through the tunnel for the same levels.

In PEVS, the smoke produced from the fire is exhausted from the opening in the ceiling and fresh air is drawn from the south portal. The same geometry and dimensions are used but the flow direction is inversed. The boundary conditions are modified to suit this change. 


\subsection{CO Concentration Distributions}

While $\mathrm{CO}_{2}$ is basically a contamination gas, the $\mathrm{CO}$ is a toxic gas. Thus large concentrations of $\mathrm{CO}_{2}$ may lead to suffocate but a relative small proportion of $\mathrm{CO}$ is lethally poisonous. The sever toxicity of $\mathrm{CO}$ implies that large concentrations of the gas should not be accumulated inside the tunnel for a long period. The maximum tolerable rate of $\mathrm{CO}$ which may be used as a criterion for considering a smoke free zone can be established as 800 ppm, NFPA [18]. The CO concentration is directly obtained from the $\mathrm{CO}_{2}$ results of the model. Approximately, there is $1 \mathrm{ppm}$ of $\mathrm{CO}$ for every $20 \mathrm{ppm}$ of $\mathrm{CO}_{2}$ for non-stoichometric combustion, [20]. Figure (3) shows $\mathrm{CO}_{2}$ contours in the tunnel symmetry plane at different fire sizes for both PSVS and PEVS.

For PSVS, $\mathrm{CO}_{2}$ concentration inside the tunnel ranges from 0 to $2500 \mathrm{ppm}$ (corresponds to $\mathrm{CO}_{2}$ mass fraction of 0.085 ) at $5 \mathrm{MW}$ fire. $\mathrm{CO}$ propagation is assured towards the south portal and a large CO-free region is established along the tunnel. For moderate HRR ( 10 and $20 \mathrm{MW}$ ) there is a relatively small production of smoke and a balance between the production of toxic gases and its transport due to air movement which avoids the presence of high $\mathrm{CO}$ concentration. The $\mathrm{CO}$ concentration is quite acceptable. In case of $40 \mathrm{MW}$ fire, due to a major heat release, maximum values of concentration reaches 0.135 mass fraction of $\mathrm{CO}_{2}$ corresponds to $6500 \mathrm{ppm} \mathrm{CO}$. The $\mathrm{CO}$ fills all the section between the fire location and the south portal where the $\mathrm{CO}$ concentration is more than $800 \mathrm{ppm}$ as shown. 


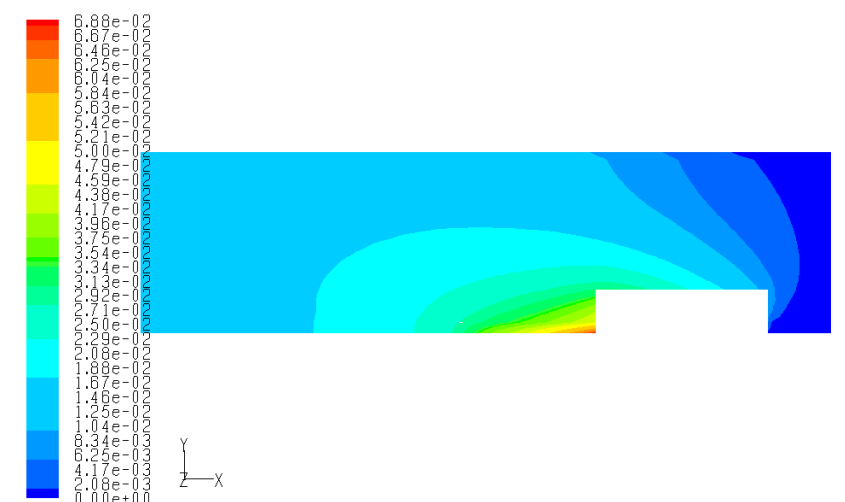

(A1): 5 MW fire size - PSVS

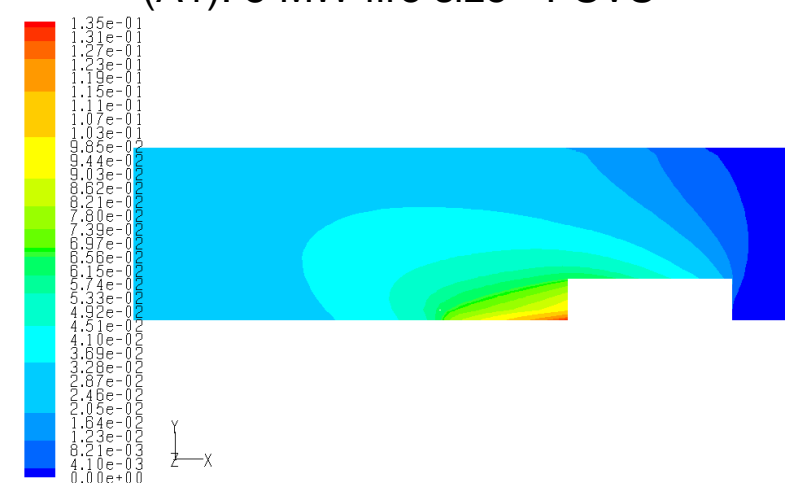

(B1): $10 \mathrm{MW}$ fire size - PSVS

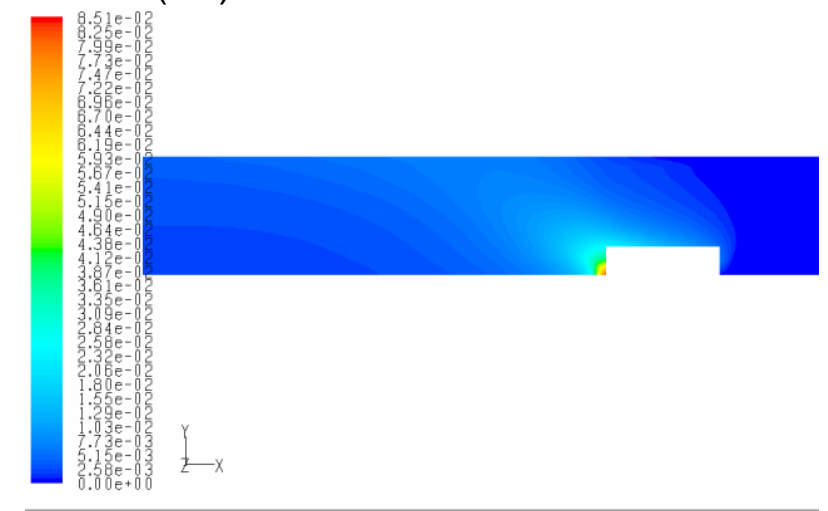

(C1) :20 MW fire size - PSVS

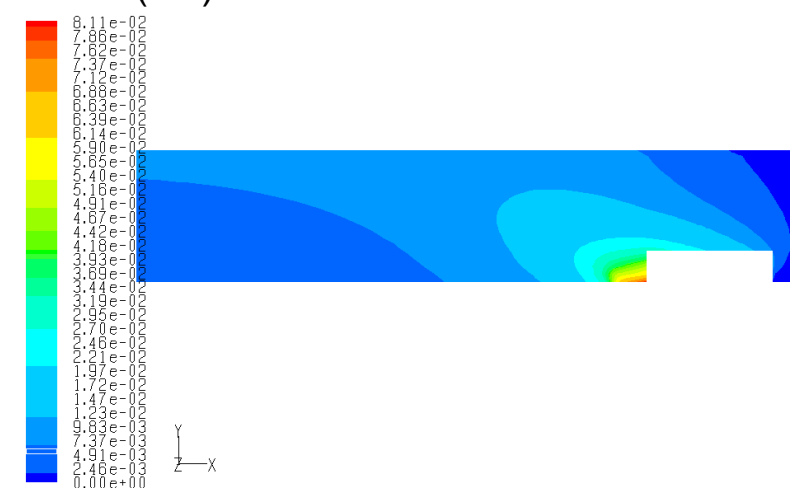

(D1) : 40 MW fire size - PSVS

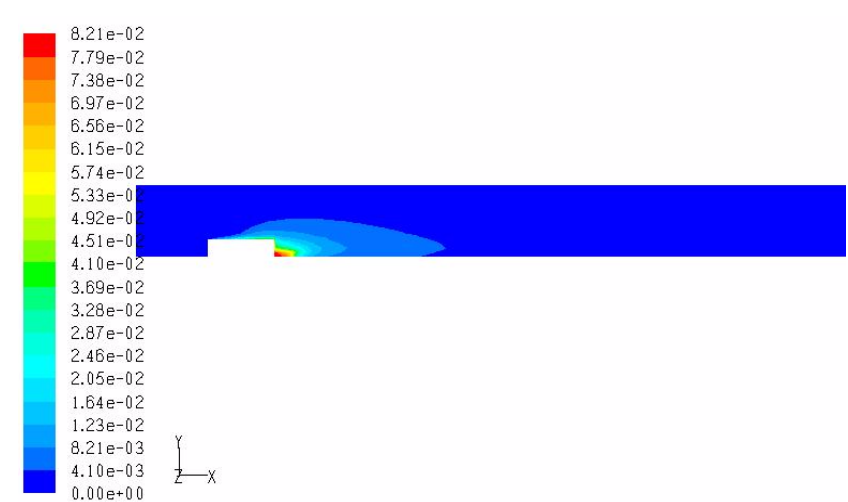

(A2): $5 \mathrm{MW}$ fire size - PEVS

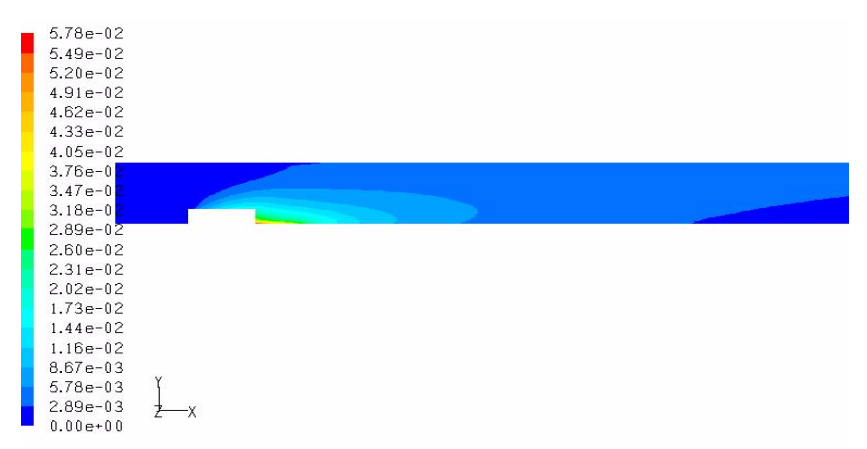

(B2): 10 MW fire size - PEVS

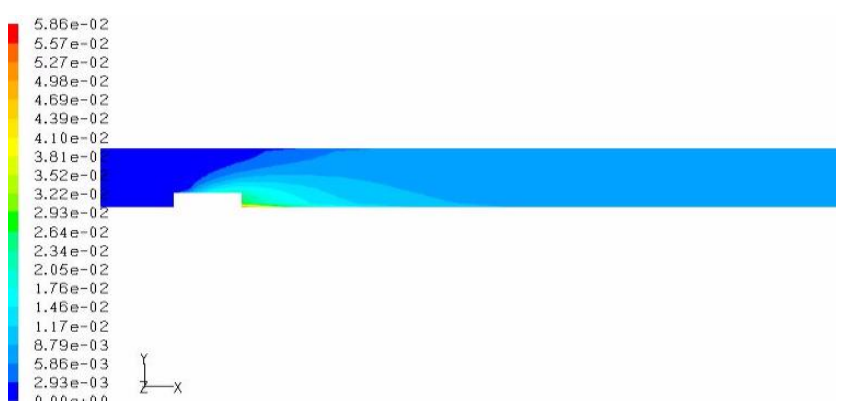

(C2) :20 MW fire size - PEVS

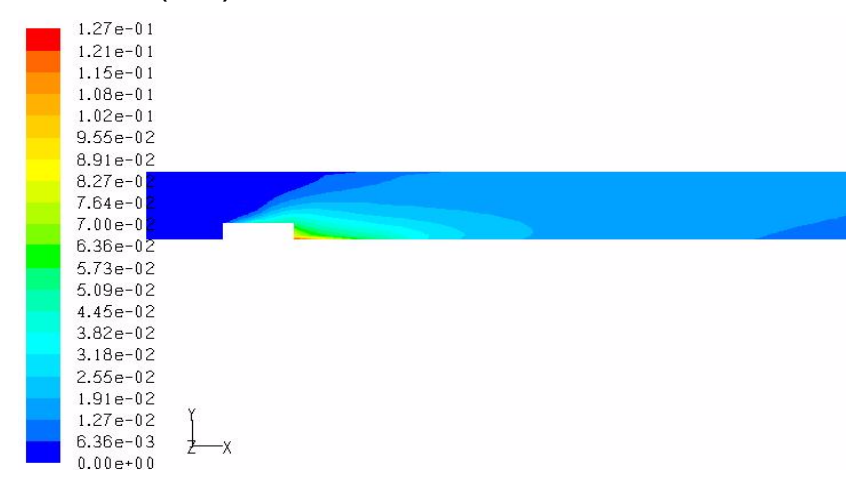

(D2) : $40 \mathrm{MW}$ fire size - PEVS

Fig (3): $\mathrm{CO}_{2}$ concentration in the symmetry plane 
Concerning the PEVS, the maximum value of $\mathrm{CO}_{2}$ which corresponds to maximum value of $\mathrm{CO}$ concentration is almost the same as PSVS. However, the distribution of $\mathrm{CO}_{2}$ indicates a significant reduction on its concentration compared with PSVS. This can be attributed to the relative location of exit port from the fire source which is approximately half of the distance between the south portal and the fire location in PSVS. This situation make the sweeping of the combustion gases toward the exit port by the air current is easier. This sweeping action reduces the pollution of the air inside the tunnel.

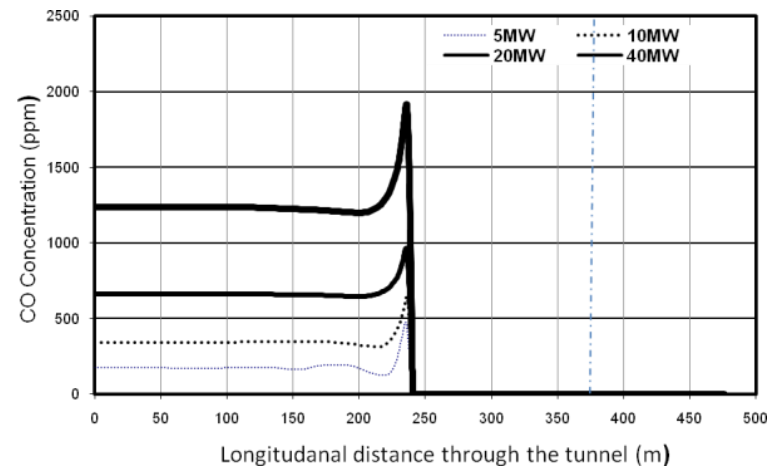

(A1): at height of $2 \mathrm{~m}$ - PSVS

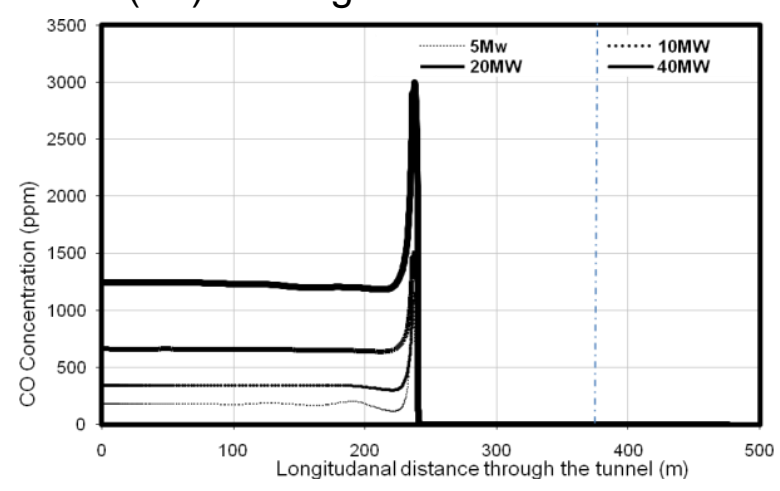

(B1): at height of $1 \mathrm{~m}$ - PSVS

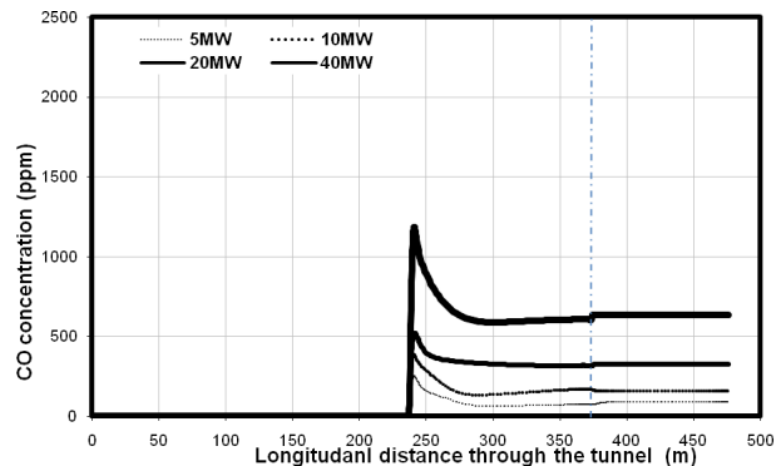

(A2): at height of $2 m$ - PEVS

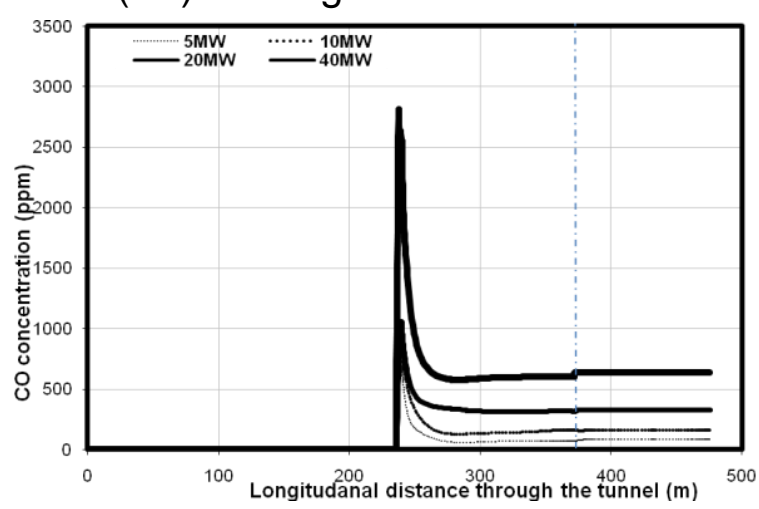

(B2): at height of $1 \mathrm{~m}$ - PEVS

Fig (4): $\mathrm{CO}$ concentration on a longitudinal line through the tunnel

To quantify the above results, $\mathrm{CO}$ concentrations were plotted against the longitudinal distance through two lines located in the symmetry plane ( $2 \mathrm{~m}$ and $1 \mathrm{~m}$ height, respectively) as shown in figure (4). Generally, the $\mathrm{CO}$ concentration increases as the fire size increases due to the increase in amount of fuel consumption. Also, PEVS has smaller asymptotic values of CO concentration compared with PSVS. However, PSVS reaches asymptotic values at shorter distance from fire source compared with PEVS. Concerning the maximum values of $\mathrm{CO}$ concentration, PEVS has improved performance compared with PSVS especially at $2 \mathrm{~m}$ level, where the induced effect due to the exhaust fan is more significant. Concerning the hazard area extension, the PEVS performs better than PSVS for all studied cases. 


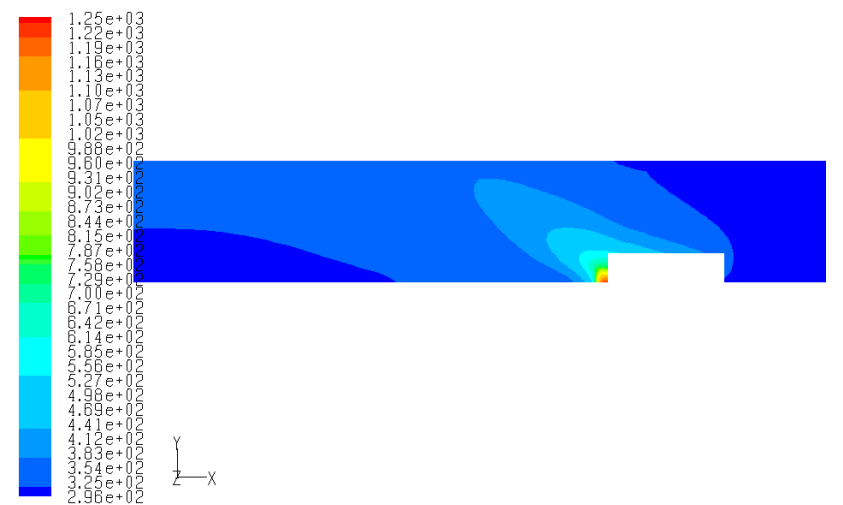

(A1): $5 \mathrm{MW}$ fire size - PSVS

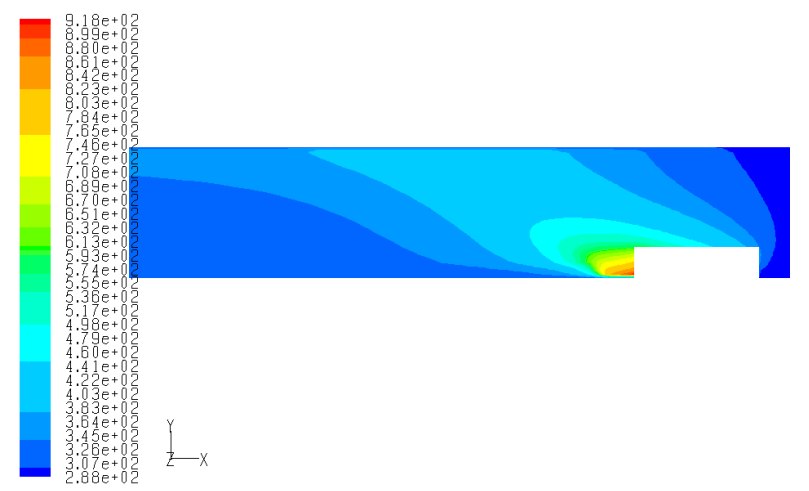

(B1): $10 \mathrm{MW}$ fire size - PSVS

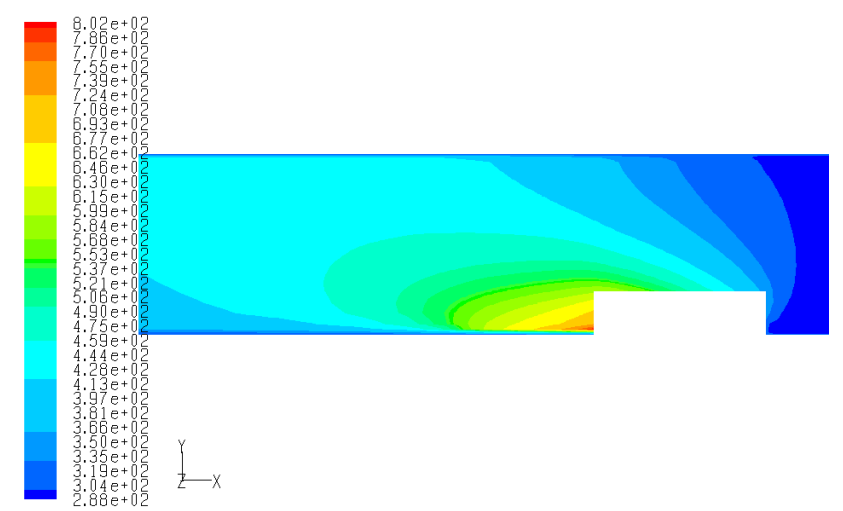

(C1) :20 MW fire size - PSVS

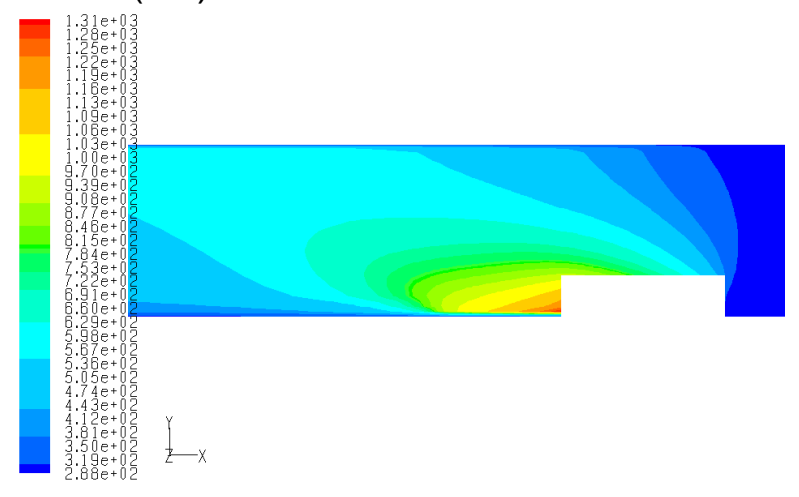

(D1) : 40 MW fire size - PSVS

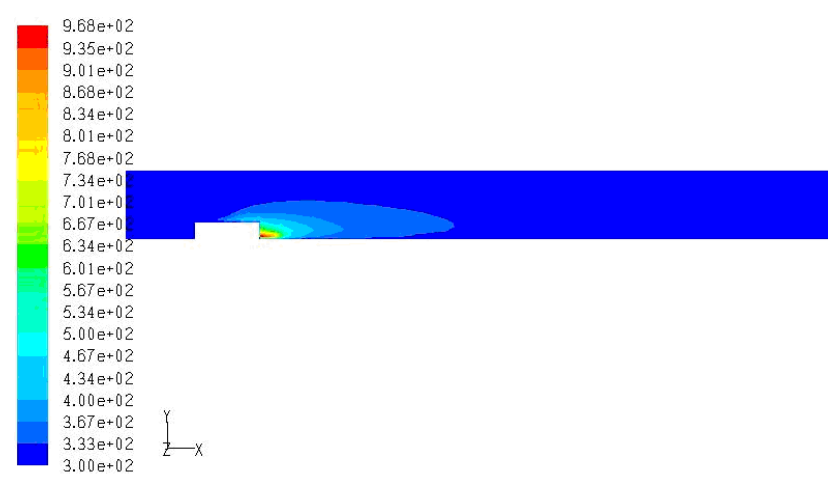

(A2): $5 \mathrm{MW}$ fire size - PEVS

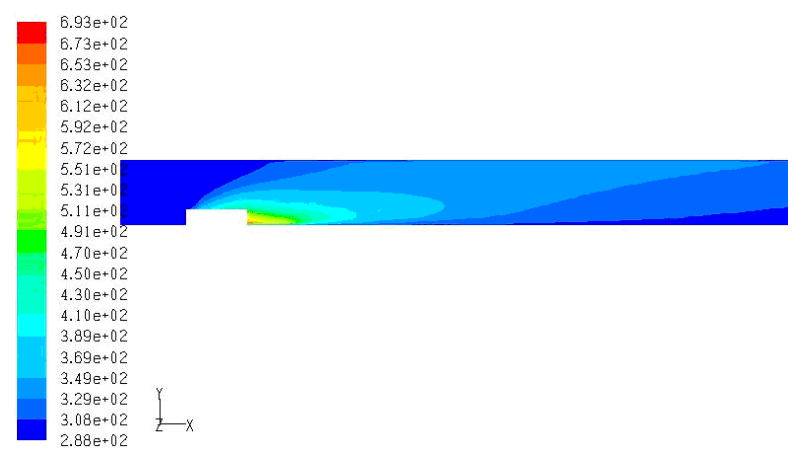

(B2): $10 \mathrm{MW}$ fire size - PEVS

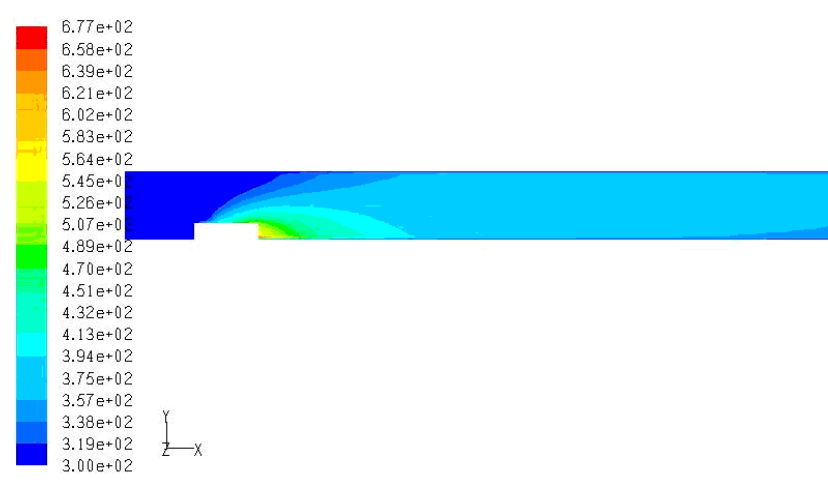

(C2) :20 MW fire size - PEVS

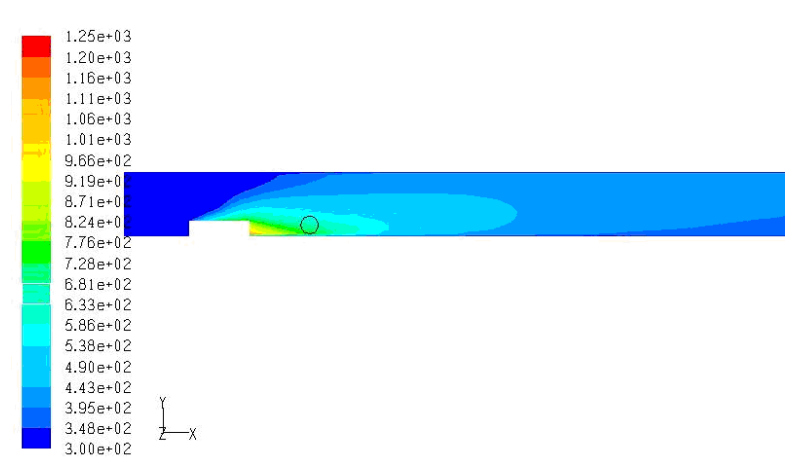

(D2) : $40 \mathrm{MW}$ fire size - PEVS

Fig (5): Temperature distribution in the symmetry plane 


\subsection{Temperature Distributions}

The ventilation system introduced fresh air that contributing to reduce the thermal map inside the tunnel. The ventilation system must keep a bearable temperature in the affection zone of the people. The maximum tolerable temperature which may be used as a criterion for considering a safe zone can be established as $60{ }^{\circ} \mathrm{C}$, NFPA [18]. Figure (5) shows the temperature distribution in the symmetry plane for fire sizes of 5 , 10,20 and $40 \mathrm{MW}$, respectively. The maximum temperature is found beside the fire location in the downstream direction in the regions of small air movement. The area affected by the fire is shown to increase as fire size increases. The stratification of the air is more obvious at smaller fire sizes. The temperature in upstream direction is quiet low compared with the temperature in downstream direction. The above statements are valid for both ventilation systems. However, the temperature distribution through the symmetry plane indicates a significant reduction of temperature throughout the tunnel for PEVS compared with PSVS.
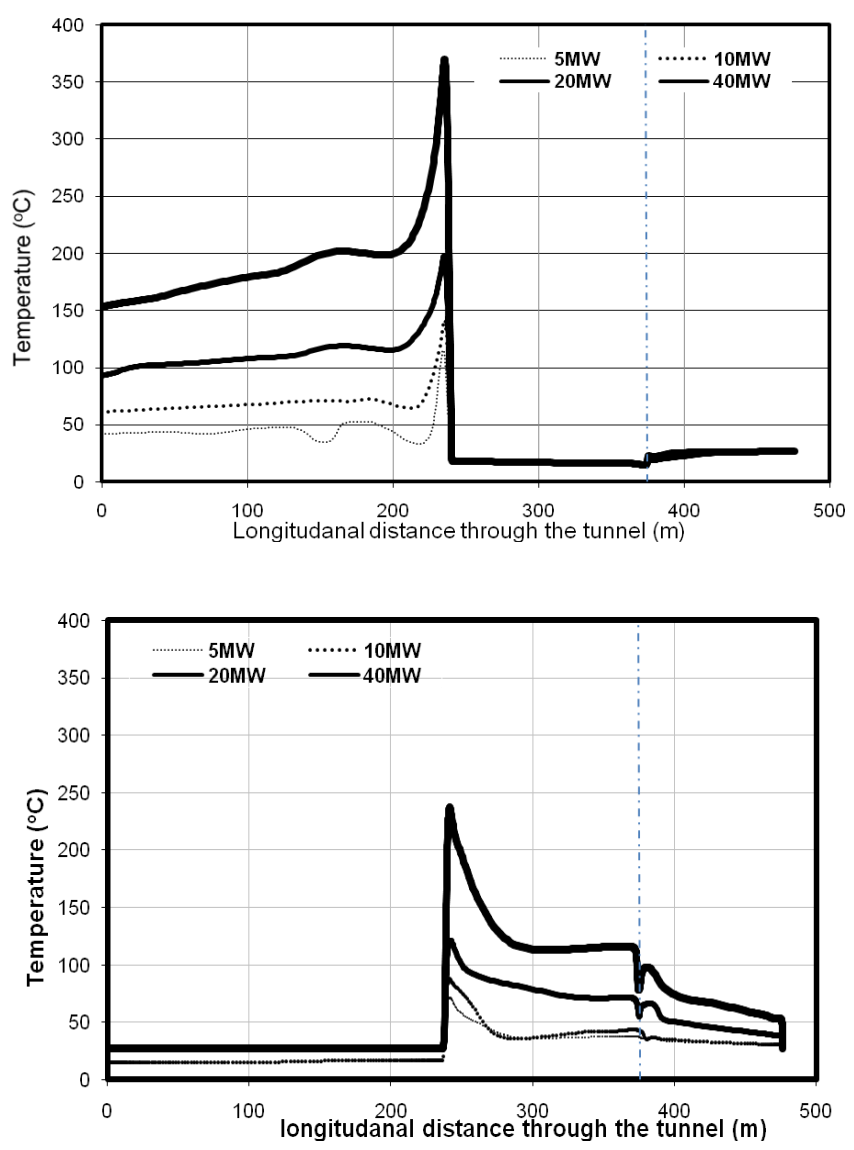

(A1): at height of $2 \mathrm{~m}$ - PSVS (A2): at height of $2 \mathrm{~m}$ -

PEVS

(A1): at height of $2 m$ - PSVS (A2): at height of $2 \mathrm{~m}$ -

PEVS

(A1): at height of $2 m$ - PSVS (A2): at height of $2 \mathrm{~m}$ -

PEVS

(A2): at height of $2 \mathrm{~m}$ -

PEVS 

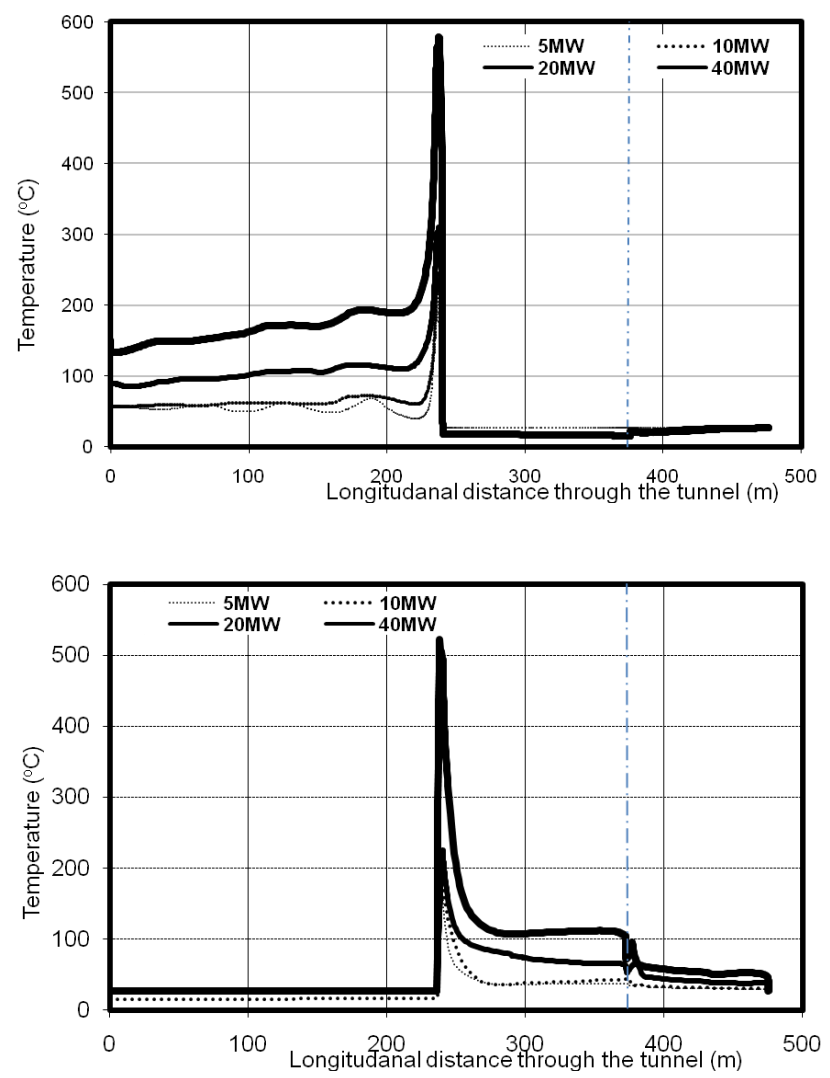

(B1): at height of $1 \mathrm{~m}$ - PSVS (B2): at height of $1 \mathrm{~m}$ - PEVS Fig (6):

(B1): at height of $1 \mathrm{~m}$ - PSVS (B2): at height of $1 \mathrm{~m}$ - PEVS Fig (6):

(B1): at height of $1 \mathrm{~m}$ - PSVS (B2): at height of $1 \mathrm{~m}$ - PEVS Fig (6): Temperature 3

(B2): at height of $1 \mathrm{~m}$ - PEVS Fig (6):

Fig (6): Temperature distribution on a

Fig (6): Temperature distribution on a longitudinal line through the tunnel

Figure (6) illustrates the temperature distribution along the tunnel symmetry plane at $1 \mathrm{~m}$ and $2 \mathrm{~m}$ heights for both ventilation systems. Compared with PSVS, the maximum temperature, at fire source, and minimum temperature, far downstream 
direction, for PEVS was found to decrease about $100^{\circ} \mathrm{C}$ for all studied cases. It is shown that, the effect of opening port is more significant for PEVS compared with PSVS. Also, the steady state conditions prevail at shorter distance for PEVS compared with PSVS.

The hazard areas based on data in figures (4) and (6) are summarized in table (1). For PSVS, the hazard area concerning $\mathrm{CO}$ concentration extends all the downstream zone of the tunnel at $40 \mathrm{MW}$ fire size. Also, the hazard areas concerning high temperature prevail throughout the downstream zone of the tunnel for 20 and $40 \mathrm{MW}$ fire sizes. For $5 \mathrm{MW}$ fire size; the extension of hazard area is $7 \mathrm{~m}$ and $10 \mathrm{~m}$ at height of $1 \mathrm{~m}$ and $2 \mathrm{~m}$, respectively. For 10 MW fire size; at a height of $1 \mathrm{~m}$ the temperature decreases to less than $60^{\circ} \mathrm{C}$ at $170 \mathrm{~m}$ from the fire centre line. While, at a height of $2 \mathrm{~m}$ the temperature does not decrease below $60^{\circ} \mathrm{C}$ at all.

Concerning the PEVS, all the downstream direction of the tunnel is considered as a hazard area for 20 and $40 \mathrm{MW}$ fire sizes. As indicated, the results show that the extension of the hazard area concerning $\mathrm{CO}$ concentration and temperature decreases with using PEVS than using PSVS.

Table (1): The extension of the hazard area for different fire sizes

Fire size

(MW) CO concentration

CO concentration Temperature

Temperature

Height of $2 m$

Height of $2 m$ Height of $1 m$

Height of $1 \mathrm{~m}$ Height of $2 \mathrm{~m}$

Height of $2 \mathrm{~m}$ Height of $1 \mathrm{~m}$

Height of $1 \mathrm{~m}$

\begin{tabular}{ll}
\multicolumn{2}{c}{ PS } \\
PS \\
PE \\
PS \\
PE \\
PE \\
PS
\end{tabular}


5

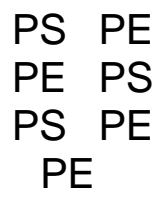

5 None None None

None 3

3 None None 10

109

97

$7 \quad 12$

12

10

10 None
None None
None 3.5
3.52
$2 \quad$ All
All 21
$21 \quad 170$
$\begin{gathered}170 \quad 18 \\ 18\end{gathered}$

20

208

8 None None 9.5

9.53

3 All

All 149

149 All

All 96

96

40

40 All

All 18

18 All

All 19

19 All

All 211

211 All

All 177

177

\subsection{Visibility Conditions}

Unlike temperature or toxic gases, obscured visibility is not, itself, lethal. A hazard 
results only if the reduced visibility prevents required action of escape activity. Visibility is often determined as the distance at which an object is no longer visible. Visibility limit can be calculated from the following correlation [21]

$$
V I=\frac{k_{v}}{\operatorname{Ln} 10} \frac{u A H_{l}}{Q D_{m}}
$$

Where $k_{v}$ is a constant. For objects such as walls, floors and doors in an underground arcade or long corridor $k_{v}=2$, while $k_{v}=6$ for illuminated signs. The values of $D_{m}$ for different types of vehicles are given based on experimental data [22]. The minimum tolerable visibility which may be used as a criterion for considering a safe zone can be established as $9 \mathrm{~m}$, NFPA [18]. The extension of hazard area can be determined as the distance from the fire centre line that has a visibility limit lower than $9 \mathrm{~m}$ for illuminated objects $\left(\mathrm{k}_{\mathrm{v}}=6\right)$.

Figure (7) shows the visibility limit in the downstream direction of fire for both of ventilation systems in the tunnel symmetry plane at heights of $2 \mathrm{~m}$ and $1 \mathrm{~m}$, respectively. The results of PSVS show that the visibility limit always less than $9 \mathrm{~m}$ downstream the fire location for all fire sizes. While, the visibility limit always higher than $9 \mathrm{~m}$ downstream the fire location for PEVS at all fire sizes. This is true, until the location of the exhaust opening where the visibility limit drops suddenly due to the decrease in air/smoke axial velocity. Generally, these above results indicate that PSVS is not suitable from the point of view of escape activity.

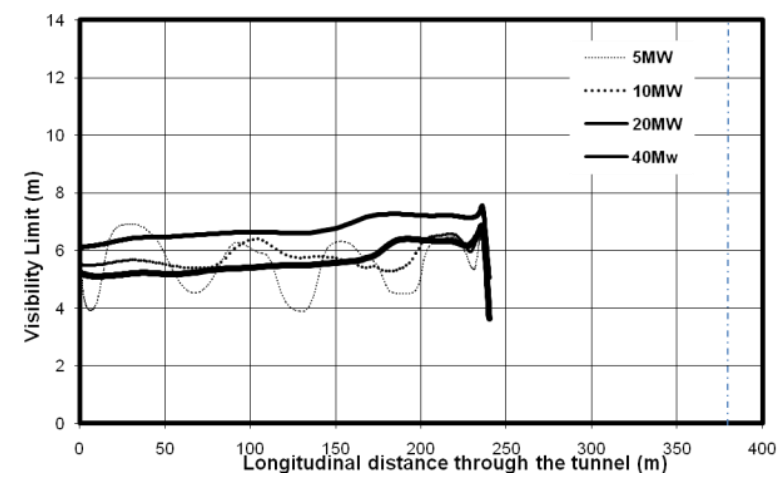

(A1): at height of $2 \mathrm{~m}$ - PSVS

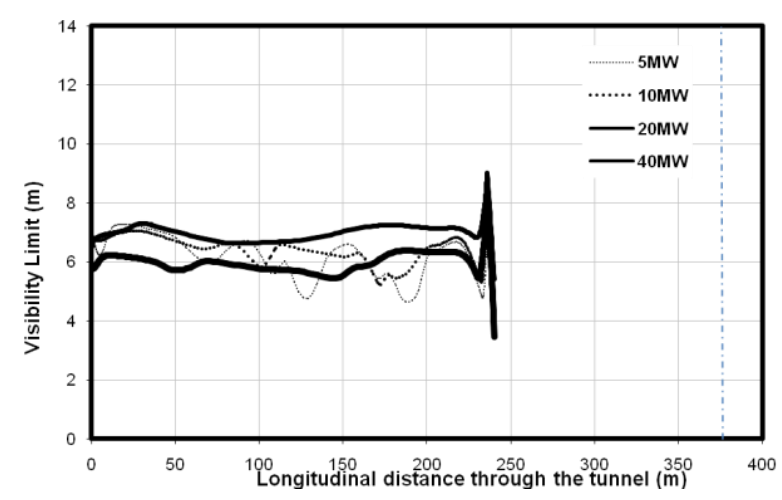

(B1): at height of $1 \mathrm{~m}$ - PSVS

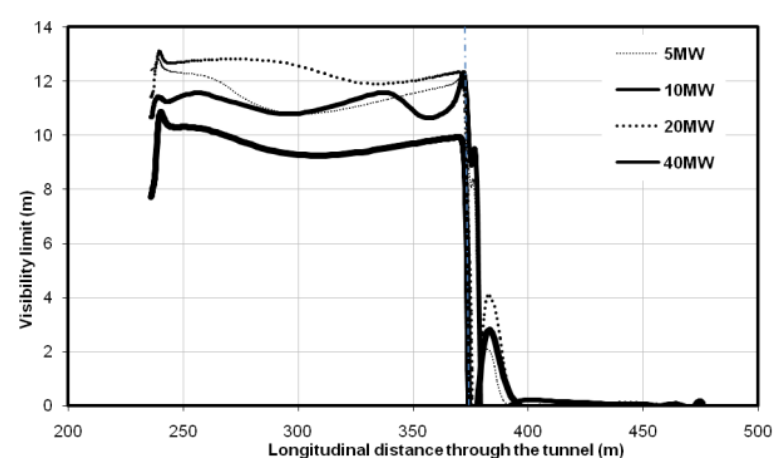

(A2): at height of $2 m$ - PEVS

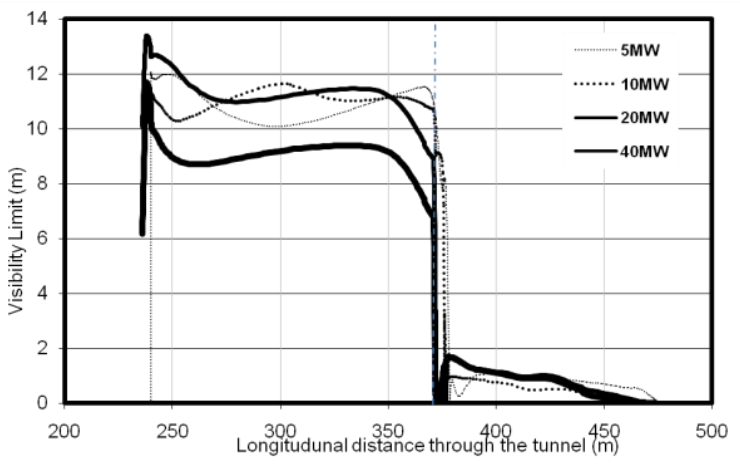

(B2): at height of $1 \mathrm{~m}$ - PEVS

Fig (7): Visibility limit on a longitudinal line through the tunnel

4. Conclusions: 
CFD technique is now reaching a mature state and gaining acceptance for tunnel applications. It has the potential both in design phase and as a design-verification tool. It could be used as a predictive tool of detailed parametric studies that would be too expensive to undertake by full-scale experiment. In this study, numerical simulation using commercial general purpose CFD software (FLUENT ver. 6.3) was used to predict the overall tunnel flow field under fire conditions and to give estimates of the temperatures, visibility and $\mathrm{CO}$ distribution throughout the tunnel. Simulation results enabled to determine the hazard areas in each studied case. PEVS accomplishes the thermal environment limitations established by NFPA standard almost at all fire sizes, namely; 5, 10, 20, and $40 \mathrm{MW}$. While, PSVS fails to do at fire sizes higher than $5 \mathrm{MW}$. These conclusions are true for the range of fire sizes and tunnel configuration considered in this study. However, it is recommended to use multiple openings at different locations on the tunnel ceiling according to the fire location; one or more opening (the closest to the fire location) can be chosen to operate. 


\section{References:}

[1] Fire and Smoke Control in Road Tunnels, PIARC Committee on Road Tunnels (C5), 1999.

[2] Kennedy WD, Gonzales JA, Sanchez JG. Derivation and application of the SES critical velocity equations. ASHRAE Trans: Research; 102(2): 40-4, 1996.

[3] Wu Y. and. Bakar M.Z.A." Control of Smoke in Tunnel Fires Using Longitudinal Ventilation Systems- a Study of the Critical Velocity", Fire Safety J; 35: 363-390, 2000.

[4] Kunsch JP. Simple model for control of fire gases in a ventilated tunnel. Fire Safety J; 37: 67-81, 2002.

[5] EUREKA-Project EU499:FIRETUN "Fires in Transport Tunnels: Report on full-scale tests”, D-40213 Dusseldorf , 1995.

[6] MHD/FHWA, "Memorial Tunnel Fire Ventilation Test Program", Comprehensive Test Report, Massachusetts Highway Dept., Federal Highway Administration, Washington, DC, 1995.

[7] P. Chasse, J.M. Apvrille, J-M: A new 1D computer model for fires in complex underground networks. In Proc. 1st Int. Conf. on Tunnel Fires and Escape from Tunnels, Lyon, France, 5-7 May 1999, pp. 201-211.

[8] I. Riess, M. Bettelini: The prediction of smoke propagation due to road tunnel fires. In Proc. 1st Int. Conf. on Tunnel Fires and Escape from Tunnels, Lyon, France, 5-7 May 1999, pp. 213-222.

[9] Charters, D.A., Gray, W.A., and Maclntosh, A.C., "A computer Model to Assess Fire Hazards in Tunnels (FASIT)", Fire Technology, Volume 30, N 1, First Quarter 1994.

Kumar, S. and Cox, G., "Mathematical Modeling of Fire in Road Tunnels -Effects of

[10] Radiant Heat and Surface Roughness," Transport and Road Research Laboratory Contractor Report No.101, Crowthom, 1988.

Armstrong, J., Bennett, E.C., Matthews, R.D., Smith, T.W. and Tabarra, M., "The

[11] Ventilation of Vehicle Tunnels by Jet Fans -The Axi-symmetric Case," Proceedings of the Seminar on Installation Effects in Fan Systems, pp. 59-64, Mechanical Engineering Press, London, 1993.

[12] Rhodes, N., "Smoke Modeling \& Critical Velocity in Tunnels", ITC Conference, London, 1996.

[13] Kang K., MacDonald H. M. "Computational study of longitudinal ventilation control during an enclosure fire within a tunnel" journal of fire protection Engineering, vol. 16-August 2006.

[14] Ballestros R., Santolaria C. and Blanco E. " Influence of the slope in the ventilation Semi-transversal System of an Urban Tunnel" Tunneling and Underground Space technology; 31: 21-28, 2006.

[15] Cochard S., "Fire Dynamics Simulator Version 2.0 for simulating tunnel fires" Tunnel Management International, Vol. 6, Issue 4, 2003.

[16] S. Miles, S. Kumar, R. Andrews: Validation of a CFD model for fires in the Memorial Tunnel, In Proc. 1st Int. Conf. on Tunnel Fires and Seminar on Escape from Tunnels, 5-7 May 1999, Lyon, France, pp. 159-168.

[17] Khadour N., ElMaihy A., Gomah A. and Elshamareka S. " Numerical Prediction of the Critical Velocity for Forced Ventilation Road Tunnel ", accepted in the $14^{\text {th }}$ AMME Conference, 25-27 May, 2010.

[18] National Fire Protection Association, "NFPA 502 Standards for Road Tunnels, Bridges, and Other Limited Access Highways", NFPA, USA, 2001.

[19] FLUENT 6.2 Documentation, (c) Fluent Inc. 2005-01-04.

20] Vega M. G., Diaz K. M. A., OroJ. M. A., Ballesteros R., Sanrolaria C. "Numerical 3D 
simulation of a longitudinal Ventilation systems: Memorial Tunnel Case" Tunneling and underground space technology; 2007.

[21] John O. B. and Kuesel T.R., "Tunnel Engineering Handbook", Van Nostrand Reinhold company, Inc, 1982.

[22] Beard, A. and Carvel, R. "The hand book of tunnel fire safety", Thomas Telford Publishing, London, 2005.

Nomenclatures
A The cross-sectional area of the tunnel $\left(\mathrm{m}^{2}\right)$
$D_{m} \quad$ Mass optical density for materials $\left(\mathrm{m}^{2} / \mathrm{kg}\right)$
$\mathrm{H}_{\mathrm{l}} \quad$ Lower heating value of fuel $(\mathrm{kJ} / \mathrm{kg})$
$\dot{Q} \quad$ Heat release rate from the fire (MW)
$\mathrm{u} \quad$ The longitudinal velocity $(\mathrm{m} / \mathrm{s})$
VI Visibility through irritant smoke $(\mathrm{m})$

Abbreviations

CFD Computational Fluid Dynamics

HRR Heat Release Rate

MTFVTP Memorial Tunnel Fire Ventilation Test Program

NFPA National Fire Protection Association

PEVS Point Exhaust Ventilation System

PSVS Point Supply Ventilation System 